Objectives: This study aims to assess the association between PTX 3 levels, disease activity and CVD risk in patients with PSA.

Methods: A total of 38 PsA patients applying to Ankara University Faculty of Medicine, Rheumatology Polyclinic and 32 age and sex-matched controls were enrolled in the study. tender and swollen joint counts, patient's and doctor's global assesment on VAS, ESR, CRP, fasting insulin, fasting glucose, total cholesterol, $\mathrm{HDL}$, and LDL were noted. Also body mass index (BMI) and HOMA-IR score were calculated. Carotid intima media thickness (cIMT) was bilaterally assessed by Doppler ultrasound.

Results: The mean age was 49.5 in patients and 48.9 in controls. Sixty percent of the patients and $50 \%$ of controls were female. Of the patients, 15 $(39 \%)$ used DMARD monotherapy, $8(21 \%)$ used DMARD combination therapies, and $15(39 \%)$ used anti TNF therapies. There was no statistically significant difference between groups in terms of hypertension, LDL levels, and smoking status ( $\mathrm{p}: 0.775, \mathrm{p}: 0.228, \mathrm{p}: 0.136$ respectively). PsA patients had significantly higher BMI scores ( $\mathrm{p}: 0.03)$. Insulin levels and HOMA-IR scores were significantly higher among PsA patients compared to controls ( $p: 0.001, p: 0.005)$. There was statistically significant difference between groups in terms of PTX $3(p<0.001)$. PTX 3 was significantly correlated with HOMA-IR and cIMT ( $r: 0.243$ p:0.043 and $r: 0.421$ p:0.001 respectively). However no correlation between PTX 3 and disease activity parameters such as ESR, CRP, SJC, TJC, and VAS-pain was detected $(\mathrm{p}: 0.824,0.662,0.922,0.924,0.410$ respectively). There was not significant difference in terms of PTX-3 levels between PsA patients on biologic treatment or other treatment strategies ( $\mathrm{p}: 0.27)$.

Conclusions: Elevated levels of PTX 3 may be associated with cardiovascular involvement in PsA patients independent from the disease activity. This marker might be used for risk prediction for CVD or may represent a target for new therapies.

References:

[1] Braun J. New targets in psoriatic arthritis. Rheumatology (Oxford). 2016 Dec;55(suppl 2).

[2] Egeberg A. Psoriasis and comorbidities. Epidemiological studies. Dan Med J.2016 Feb;63(2).

[3] Rutter MK, Kane K, Lunt M, et al. Primary care based screening for cardiovascular risk factors in patients with psoriasis. Br J Dermatol. 2016 Mar 1.

[4] Inoue K, Kodama T, Daida H. Pentraxin 3: a novel biomarker for inflammatory cardiovascular disease Int J Vasc Med. 2012;2012:657025.

Disclosure of Interest: None declared

DOI: 10.1136/annrheumdis-2017-eular.3757

\section{AB0763 USTEKINUMAB FOR THE TREATMENT OF PSORIATIC ARTHRITIS - RESULTS OF THE FIRST INTERIM ANALYSIS OF THE NON-INTERVENTIONAL STUDY SUSTAIN}

J. Wendler $^{1}$, I. Schwarze ${ }^{2}$, H. Schwenke ${ }^{3}$, J. Behrens ${ }^{4}$, T. Gruppe ${ }^{4}$, F. Behrens ${ }^{5} .{ }^{7}$ Rheumatologische Schwerpunktpraxis, Erlangen; ${ }^{2}$ Praxis für Internistische Rheumatologie, Leipzig; ${ }^{3}$ Rheumatologisches MVZ Dresden, Dresden; ${ }^{4}$ Janssen-Cilag GmbH, Neuss; ${ }^{5}$ CIRI/Rheumatology \& Fraunhofer TMP, Frankfurt, Germany

Objectives: SUSTAIN is a prospective, multi-center non-interventional study in Germany to observe long term efficacy and safety, quality of life and further patient reported outcomes in patients with active psoriatic arthritis under treatment with Ustekinumab in routine clinical care.

Methods: In this study treatment with Ustekinumab is according to the label $\left(\right.$ Stelara $\left.^{\circledR}\right)$. It is planned to observe 400 patients at 75 centers for 160 weeks with documentation intervals at week 0 and 4 and then every 12 weeks. Besides demographic data, the following data will be documented: Amount of swollen and tender joints, tender entheses, skin symptoms (BSA and PASI), patient reported outcome concerning disease activity and pain, Health Assessment Questionnaire (HAQ), quality of life (SF-12), sleep quality (VAS), satisfaction with therapy of patient and physician, safety (adverse events [AE]/serious adverse events [SAE]), pharmacoeconomic aspects, number of patients with "Minimal Disease Activity" (MDA), number of patients with MDA at week 28 und 52.

Results: Overall, there have been 189 patients (56\% women) at 59 centers documented after 11 months. At week 4154 patients and at week 16112 patients. At baseline, the patients had a mean age of 56 years (29-85), body weight $87 \mathrm{~kg}(50-147)$, BMI 30 (19-47), showed arthritis at small (68.8\%) and/or big $(51.3 \%)$ joints, skeletal involvement (19\%), enthesitis (13.2\%). The number of tender joints improved from a mean of $8,6(\mathrm{Cl} 95 \% 7.1 / 10.2)$ to $4.7(3.1 / 6.3)$ at week 16 , number of swollen joints from $3,4(2,6 / 4,2)$ to $1,4(0.9 / 1.9)$. The patient reported global disease activity $(0-100)$ decreased from 55.1 to 38.6 at week 16. Further improvements were documented for enthesitis, PSA, BSA, PASI, and pain. Efficacy of the therapy with Ustekinumab after 16 weeks was assessed as "very good" by $32.3 \%$ and as "good" by $44.8 \%$ of the treating physicians and by $34 \%$ and $40.2 \%$, respectively, of the patients. In total, 60 adverse events were reported, of which four were serious. All in all safety of therapy with Ustekinumab after 16 weeks was assessed as "very good" by $51 \%$ and as "good" by $43.8 \%$ of the treating physicians, and by $55 \%$ and $37 \%$, respectively, of the patients. Conclusions: The non-interventional study SUSTAIN showed relevant improvements with elevated therapy satisfaction and good safety in patients with active psoriatic arthritis after 16 weeks under real world condition.
Disclosure of Interest: J. Wendler Consultant for: Janssen-Cilag GmbH, Speakers bureau: Janssen-Cilag GmbH, I. Schwarze: None declared, H. Schwenke: None declared, J. Behrens Employee of: Janssen-Cilag GmbH, T. Gruppe Employee of: Janssen-Cilag GmbH, F. Behrens Consultant for: Janssen-Cilag GmbH, Speakers bureau: Janssen-Cilag GmbH

DOI: 10.1136/annrheumdis-2017-eular.3764

\section{AB0764 MALIGNANCY AND SERIOUS INFECTIONS AMONG PSORIATIC ARTHRITIS PATIENTS TREATED WITH BIOLOGICAL DRUGS IN A REGIONAL REGISTRY IN THE NORTHWEST OF SPAIN}

J. Pinto-Tasende $^{1}$, F.J. Maceiras-Pan ${ }^{2}$, L. Guerra-Vazquez ${ }^{3}$,

L. Fernandez-Dominguez ${ }^{4}$, J.A. Mosquera-Martínez ${ }^{5}$, C. García-Porrúa ${ }^{6}$ ${ }^{1}$ INIBIC-Rheumatology, Complejo Hospitalario Universitario A Coruña, A Coruña; ${ }^{2}$ Rheumatology, Complejo Hospitalario Universitario de Vigo, Vigo; ${ }^{3}$ Rheumatology, Complejo Hospitalario Universitario de Ferrol, Ferrol;

${ }^{4}$ Rheumatology, Complejo Hospitalario Universitario de Ourense, Ourense; ${ }^{5}$ Rheumatology, Complejo Hospitalario Universitario de Pontevedra, Pontevedra; ${ }^{6}$ Rheumatology, Hospital Universitario de Lugo, Lugo, Spain

Background: Biological treatments have provided new opportunities for disease control for patients with psoriatic arthritis. However, it is important to evaluate their safety, since they expose them to an increased risk of developing malignant tumors and serious infections.

Objectives: To examine the rate of solid tumors and serious infections among patients diagnosed with psoriatic arthritis (PsA) treated with biological drugs (BD) in 2011-2015.

Methods: We included all PsA patients (CASPAR criteria) under treatment with $\mathrm{BD}$ followed in our regional registry (reference population 2.055.000) between January 2011 and December 2015. In order to capture the incidence of new malignancy we excluded patients with a prior history of malignancy. Medical records were fulfilled for patients and were recorded solid tumors diagnosed (date of diagnosis and histology information) and all serious infections (requiring hospitalization or intravenous antibiotics) in this time. Incidence rates (IRs) were calculated per 1000 Person-year (py). We used for this analysis sex, age, disease duration, current BD with or without current DMARD associated. Continuous variables were reported as mean \pm standard deviation (SD). Categorical variables were reported as percentages and frequencies. Differences were considered statistically significant if $p<0.05$ (two-tailed).

Results: Among 604 patients $329(54.5 \%)$ of whom were men, with a mean age of $53.3 \pm 12.6$ years and a time since the diagnosis of PsA of $12.4 \pm 8.7$ years. There were 14 cancers diagnosed during treatment $(2.3 \%)$, with an IR of 0.48 cases per 1000 patient-years. Patients who developed cancer had a higher age, $63.4 \pm 10.0$ years vs $53.1 \pm 12.6$, than those who did not developed $(\mathrm{p}=0.010)$. Etanercept was the most used $(42 \%)$ and no differences were observed among $\operatorname{BDs}(p=0.214)$ or between naïve and non-naïve to $B D(p=0.384)$. Current DMARD associated $(56.2 \%)$ had not differences in tumors $(p=0.429)$. Prostate tumor was the most frequent $(21.4 \%)$. There were 42 had serious infection (6.2\%), with an IR of 13.9 cases per 1000 patient-years, and was more common in men $(4.7 \%$ vs $8.8 \%, p=0.049$ ). Severe infections were more frequent in patients non-naïve to $B D$ $(10.4 \%$ vs $5.4 \%, p=0.026)$. Pneumonia $(28.6 \%)$, varicella-zoster virus infection $(16.6 \%)$ and soft tissue infections (14.3\%) were most frequent. Latent tuberculosis infection was positive in 133 patients (22.0\%) and 3 developed tuberculosis.

Conclusions: Patients older than 60 years with psoriatic arthritis treated with BDs had a higher incidence of tumor development. Most of patients were men and prostate tumor was the most frequent. Pneumonia was the most frequent serious infection and non-naïve to BD patients had a higher IR of serious infections.

[1] Malignancy incidence in patients with psoriatic arthritis: a comparison cohortbased incidence study. Wilton KM, Crowson CS, Matteson EL.Clin Rheumatol. 2016 Oct; 35(10):2603-7.

Acknowledgements: The authors are grateful for the support of the members of the Galician Society of Rheumatology (SOGARE).

Disclosure of Interest: None declared

DOI: 10.1136/annrheumdis-2017-eular.3300

\section{AB0765 SECUKINUMAB PROVIDES SUSTAINED IMPROVEMENT IN FUNCTION, QUALITY OF LIFE AND FATIGUE OVER 2 YEARS IN PATIENTS WHO ACHIEVED DISEASE ACTIVITY INDEX FOR PSORIATIC ARTHRITIS (DAPSA) REMISSION}

J.S. Smolen ${ }^{1}$, I.B. Mclnnes ${ }^{2}$, L. Gossec ${ }^{3}$, V. Strand ${ }^{4}$, L. Pricop ${ }^{5}$, T. Fox ${ }^{6}$ S. Jugl ${ }^{6}$, C. Gaillez ${ }^{6}$ on behalf of the FUTURE 2 Study Group. ${ }^{1}$ Medical University of Vienna, Vienna, Austria; ${ }^{2}$ University of Glasgow, Glasgow, United Kingdom; ${ }^{3}$ UPMC Université Paris 06, Paris, France; ${ }^{4}$ Stanford University School of Medicine, Stanford; ${ }^{5}$ Novartis Pharmaceuticals Corp., East Hanover, United States; ${ }^{6}$ Novartis Pharma AG, Basel, Switzerland

Background: Disease Activity index for Psoriatic Arthritis (DAPSA) states are associated with functional impairment levels in patients (pts) with psoriatic arthritis (PsA). ${ }^{1}$ Secukinumab demonstrated sustained improvements in disease activity assessed with DAS28-CRP, physical function and pt-reported outcomes (PROs) among active PsA pts over 104 weeks (wks) in the FUTURE 2 study. ${ }^{2}$ 
Abstract AB0765 - Table 1. Core components by DAPSA states with secukinumab or placebo at Wk 16

\begin{tabular}{|c|c|c|c|c|c|c|c|c|c|c|}
\hline \multirow[t]{2}{*}{ Mean \pm SD } & \multicolumn{2}{|c|}{ SJC (66) } & \multicolumn{2}{|c|}{ TJC (68) } & \multicolumn{2}{|c|}{ PtGA $(\mathrm{cm})$} & \multicolumn{2}{|c|}{$\mathrm{PP}(\mathrm{cm})$} & \multicolumn{2}{|c|}{$\mathrm{CRP}(\mathrm{mg} / \mathrm{dl})$} \\
\hline & $300 \mathrm{mg} / 150 \mathrm{mg}$ & PBO & $300 \mathrm{mg} / 150 \mathrm{mg}$ & PBO & $300 \mathrm{mg} / 150 \mathrm{mg}$ & PBO & $300 \mathrm{mg} / 150 \mathrm{mg}$ & PBO & $300 \mathrm{mg} / 150 \mathrm{mg}$ & $\mathrm{PBO}$ \\
\hline REM $^{*}$ & $0.4 \pm 0.7 / 0.2 \pm 0.4$ & $1.0 \pm 1.4$ & $0.2 \pm 0.4 / 0.3 \pm 0.5$ & $0.5 \pm 1.0$ & $0.6 \pm 0.5 / 0.6 \pm 0.5$ & $0.6 \pm 0.6$ & $0.7 \pm 0.7 / 0.7 \pm 0.4$ & $0.8 \pm 0.6$ & $0.3 \pm 0.3 / 0.5 \pm 0.4$ & $0.2 \pm 0.2$ \\
\hline $\mathrm{LDA}^{\wedge}$ & $1.7 \pm 2.3 / 1.4 \pm 1.6$ & $1.6 \pm 2.0$ & $2.5 \pm 1.9 / 1.8 \pm 2.2$ & $2.3 \pm 2.7$ & $2.3 \pm 1.6 / 2.1 \pm 1.2$ & $2.3 \pm 1.8$ & $2.3 \pm 1.3 / 2.3 \pm 1.3$ & $2.6 \pm 1.8$ & $0.4 \pm 0.4 / 0.4 \pm 0.7$ & $0.2 \pm 0.3$ \\
\hline $\mathrm{MDA}^{\#}$ & $4.5 \pm 3.8 / 4.9 \pm 3.0$ & $4.9 \pm 3.4$ & $6.0 \pm 4.1 / 7.0 \pm 2.8$ & $7.5 \pm 4.1$ & $3.8 \pm 2.3 / 3.9 \pm 1.9$ & $3.9 \pm 1.8$ & $4.1 \pm 2.0 / 3.8 \pm 1.8$ & $4.5 \pm 1.8$ & $0.4 \pm 0.4 / 0.9 \pm 1.0$ & $0.7 \pm 1.2$ \\
\hline $\mathrm{HDA}^{\$}$ & $10.7 \pm 7.5 / 14.4 \pm 11.1$ & $10.4 \pm 7.2$ & $24.6 \pm 12.4 / 29.2 \pm 19.0$ & $26.6 \pm 15.2$ & $4.9 \pm 1.7 / 5.6 \pm 2.0$ & $5.9 \pm 1.8$ & $5.2 \pm 1.9 / 5.6 \pm 1.8$ & $6.1 \pm 1.5$ & $0.4 \pm 0.4 / 0.6 \pm 0.7$ & $1.2 \pm 1.7$ \\
\hline
\end{tabular}

${ }^{*} \mathrm{n}=14$ (300mg), 10 (150mg) and 4 (PBO); ${ }^{n} \mathrm{n}=27$ (300mg), 34 (150mg) and 12 (PBO); ${ }^{\#} \mathrm{n}=26$ (300mg), 24 (150mg) and 22 (PBO); ${ }^{\$} \mathrm{n}=30$ (300mg), 32 (150mg) and 49 (PBO).

Objectives: To explore the relationship between DAPSA states and function, health-related quality of life and PROs, and the individual DAPSA components in the different states in pts treated with secukinumab through 104 wks using post-hoc analysis.

Methods: FUTURE 2 study design has been reported. ${ }^{3}$ DAPSA was derived as sum of five core components: tender joint and swollen joint counts (TJC 68, SJC 66), pt global assessment (PtGA) and pain (PP) assessed by a $10 \mathrm{~cm}$ VAS and CRP $(\mathrm{mg} / \mathrm{dl})$. Four DAPSA states were: remission (REM: $<4)$, low (LDA: $>4-\leq 14)$, moderate (MDA:>14- $\leq 28$ ) or high disease activity (HDA: $>28$ ). Mean \pm SD of each core component of DAPSA were analysed at Wks 16, 24, 52 and 104 using observed data. The relationship between HAQ-DI, SF-36 PCS and MCS, PsAQoL, DLQI and FACIT-Fatigue with DAPSA states was assessed in the pooled treatment arms at each time point using a mixed-effect model for repeated measures (MMRM) analyses.

Results: Baseline characteristics were similar across treatment groups. ${ }^{3}$ DAPSA scores at baseline (mean \pm SD) were $42.0 \pm 17.4,46.8 \pm 24.3$ and $44.9 \pm 25.3$ in the secukinumab $300 \mathrm{mg}, 150 \mathrm{mg}$ and placebo groups, respectively. Mean scores of each component by DAPSA states at Wk 16 are shown in table and were sustained through Wk 104. Significant differences were observed among secukinumab treated pts between REM vs. HDA and LDA vs. HDA states for PRO scores through Wk104 (Figure).
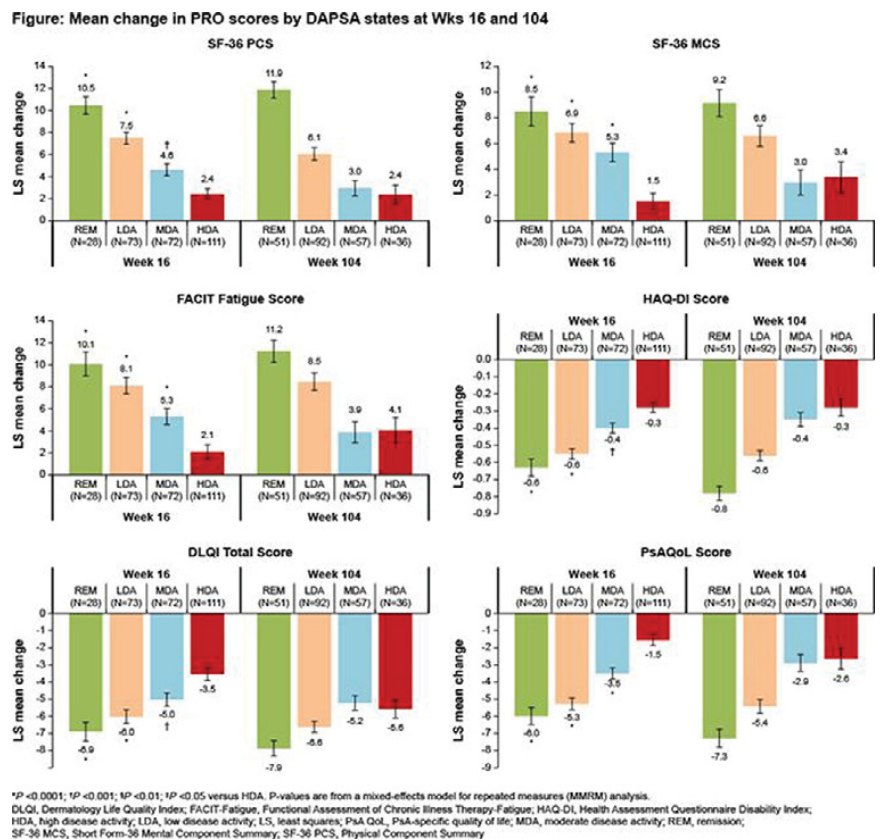

Conclusions: In pts treated with secukinumab 300 or $150 \mathrm{mg}$, the five individual components related to DAPSA REM were $<1$ in contrast with other disease states and were sustained through Wk 104. DAPSA REM was associated with significantly greater improvement in physical function, health related quality of life and fatigue indicating that it is an important target to be achieved and sustained in PsA pts.

\section{References:}

[1] Schoels MM, et al. Ann Rheum Dis 2016;75:811-8.

[2] McInnes IB, et al. Arthritis Rheumatol 2016;68(suppl 10).

[3] McInnes IB, et al. Lancet 2015;386:1137-46.

Disclosure of Interest: J. Smolen Grant/research support from: AbbVie, Janssen, Eli Lilly, MSD, Pfizer, Roche, Amgen, AstraZeneca, Astro, Celgene, Celltrion, GSK, ILTOO, Medimmune, Novartis-Sandoz, Pfizer, Samsung, Sanofi and UCB., Consultant for: AbbVie, Janssen, Eli Lilly, MSD, Pfizer, Roche, Amgen, AstraZeneca, Astro, Celgene, Celltrion, GSK, ILTOO, Medimmune, Novartis-Sandoz, Pfizer, Samsung, Sanofi and UCB., I. McInnes Grant/research support from: AbbVie, Amgen, BMS, Celgene, Janssen, Lilly, Novartis, Pfizer and UCB, Consultant for: AbbVie, Amgen, BMS, Celgene, Janssen, Lilly, Novartis, Pfizer and UCB, L. Gossec Grant/research support from: UCB, Eli Lilly and Pfizer; Consultant for AbbVie, BMS, Celgene, Janssen, Novartis, Pfizer and Roche, V. Strand Consultant for: AbbVie, Amgen, BMS, Celgene, Celltrion, Corrona, Genentech/Roche, GSK, Janssen, Lilly, Merck, Novartis, Pfizer, Regeneron, Samsung, Sanofi and UCB, L.
Pricop Shareholder of: Novartis, Employee of: Novartis, T. Fox Shareholder of: Novartis, Employee of: Novartis, S. Jugl Shareholder of: Novartis, Employee of: Novartis, C. Gaillez Shareholder of: Novartis and BMS, Employee of: Novartis DOI: 10.1136/annrheumdis-2017-eular.3648

\section{AB0766 SECUKINUMAB PROVIDES SUSTAINED REMISSION AND LOW DISEASE ACTIVITY RELATED TO DISEASE ACTIVITY INDEX FOR PSORIATIC ARTHRITIS (DAPSA): 2 YEAR RESULTS FROM THE FUTURE 2 STUDY}

J.S. Smolen ${ }^{1}$, I.B. Mclnnes ${ }^{2}$, T.K. Kvien ${ }^{3}$, L. Pricop ${ }^{4}$, T. Fox ${ }^{5}$, L. Rasouliyan ${ }^{6}$, S. Jugl ${ }^{5}$, C. Gaillez ${ }^{5}$ on behalf of the FUTURE 2 Study group. ${ }^{1}$ Medical University of Vienna, Vienna, Austria; ${ }^{2}$ University of Glasgow, Gasgow, United Kingdom; ${ }^{3}$ Diakonhjemmet Hospital, Oslo, Norway; ${ }^{4}$ Novartis Pharmaceuticals Corp., East Hanover, United States; ${ }^{5}$ Novartis Pharma AG, Basel, Switzerland; ${ }^{6}$ RTI Health Solutions, Barcelona, Spain

Background: Disease Activity Index for Psoriatic Arthritis (DAPSA) is a validated tool to measure disease activity states, focussing on peripheral joint involvement in psoriatic arthritis (PsA), and can be used to assess targets such as remission (REM) or low disease activity (LDA). ${ }^{1}$

Objectives: Secukinumab, a fully human anti-interleukin-17A monoclonal antibody, significantly improved American College of Rheumatology responses vs. placebo at Week (Wk) 24 that were sustained through Wk 104 in active PsA patients (pts) in the FUTURE 2 study $^{2}$. This post-hoc exploratory analysis assessed DAPSA states through Wk 104

Methods: In total, 397 active PsA pts were randomised to subcutaneous (s.c) secukinumab $(300,150$ or $75 \mathrm{mg})$ or placebo at baseline and Wks $1,2,3$ and 4 , and every 4 wks (q4w) thereafter. Placebo pts were re-randomised to secukinumab 300 or $150 \mathrm{mg}$ s.c q4w from Wk 16 or 24, depending on Wk 16 clinical response. DAPSA was derived as the sum of five variables: tender joint and swollen joint counts (TJC 68 and SJC 66); pt global and pain assessed on a $10 \mathrm{~cm}$ visual analogue scale; and C-reactive protein levels $(\mathrm{mg} / \mathrm{dl})$ with validated cut-offs to indicate REM $(\leq 4)$, LDA ( $>4$ and $\leq 14$ ), moderate disease activity (MDA; $>14$ and $\leq 28)$ and high disease activity (HDA; $>28$ ). DAPSA was assessed in the overall population and in pts stratified by prior anti-tumour necrosis factor (anti-TNF) therapy use (anti-TNF-naïve vs. inadequate response/intolerance to these agents [anti-TNF-IR]) and time since first PsA diagnosis ( $\leq 2$ vs. $>2$ years) using observed data. Only data for secukinumab 300 and $150 \mathrm{mg}$ (approved doses) are reported.

Results: Baseline demographics and clinical characteristics were similar across treatment groups and previously reported. ${ }^{3}$ DAPSA score at baseline (mean [SD]) was 42.0 (17.4), 46.8 (24.3) and 44.9 (25.3) in the secukinumab $300 \mathrm{mg}$, $150 \mathrm{mg}$ and placebo groups, respectively. In the overall population, at Wk 16 , REM was achieved in 14/97 (14.4\%) with secukinumab 300mg and 10/100 (10\%) with secukinumab $150 \mathrm{mg}$ vs. placebo $4 / 87$ (4.6\%); LDA in $27 / 97(27.8 \%)$ and $34 / 100$ (34\%) vs. $12 / 87(13.8 \%)$, respectively. REM or LDA were sustained through Wk 104 with secukinumab 300 and 150mg (55/84 [65.5\%; REM + LDA] and 41/ 77 [53.2\%; REM + LDA], respectively). The proportion of pts achieving each DAPSA state at Wks 16 and 104 by anti-TNF status (anti-TNF-naïve vs. anti-TNF-IR)

Figure. DAPSA at Wks 16 and 104 by anti-TNF status and Disease duration
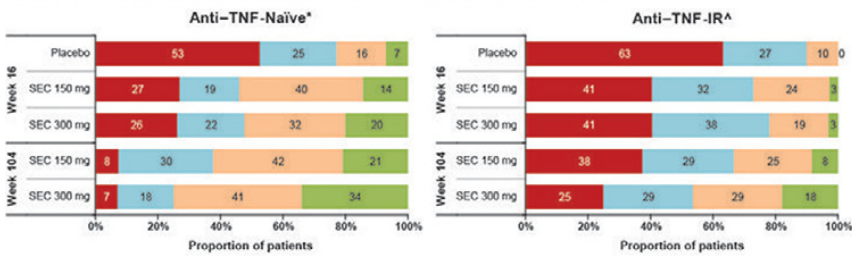

Time since first PsA diagnosis $\leq 2$ years'
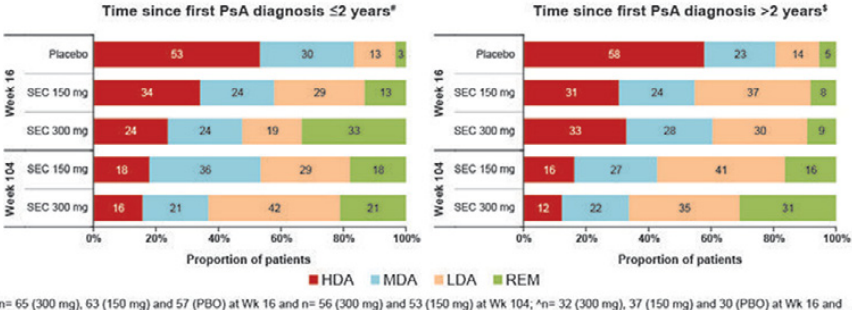

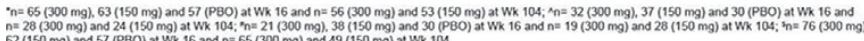

